\title{
ESTUDIO DESCRIPTIVO DE BLOQUEOS INTERESCALÉNICOS CONTINUOS
}

Fariña Roggendorf Gabriela ${ }^{1}$, Figueroa Jaddour Rodrigo ${ }^{1}$, Pinto Ramírez Lorena ${ }^{1}$, Troncoso Hugot María Ignacia ${ }^{1}$, Yarur Spencer Carlos ${ }^{1}$, Moreno Cantariño Enrique ${ }^{1}$

Clínica Santa María.

Introducción: El bloqueo interescalénico continuo proporciona analgesia postoperatoria superior a la convencional, con menores requerimientos opioides y menor incidencia de efectos colaterales, permite una más rápida recuperación de la movilidad articular y disminuye el tiempo de hospitalización. La incidencia de complicaciones de injuria nerviosa y de falla de catéter es baja.

Objetivo General: El objetivo del estudio es caracterizar al grupo que recibe bloqueo interescalénico continuo para cirugía de hombro, su analgesia y las complicaciones.

Material y Métodos: Se realizó un estudio descriptivo retrospectivo, utilizando las bases de datos electrónicas de Clínica Santa María (CSM), para analizar todas las cirugías de hombro electivas y de urgencia $(n=249)$ manejadas con bloqueo interescalénico continuo con chirocaína $0,08-0,1 \%$ por bomba elastomérica a $5 \mathrm{ml} /$ hora desde enero de 2015 hasta junio de 2016. Se contó con aprobación del comité de ética institucional. Se evaluó el dolor postoperatorio mediante Escala Visual Análoga (EVA) en reposo y dinámico el primer y segundo día posterior a la cirugía. Se caracterizó a la población intervenida por: edad, género, diagnóstico asociado y complicaciones del manejo analgésico y se de- terminó la incidencia de fallas de catéter. Los datos fueron recolectados y analizados del punto de vista estadístico en SPSS versión 20 (IBM, 2012).

Resultados: El promedio de edad fue 49 años, mayor en mujeres (57 años). La mayor proporción fueron hombres $(61 \%)$. Mediana de dolor (rango): el primer día fue $0(0-7)$ en reposo y 0 (0-10) dinámico, el segundo día fue $0(0-6)$ y 0 (0-8) respectivamente. Por categorías de dolor leve (EVA 0-3), moderado (4-7) y severo (8-10): el primer día EVA reposo fue $89,6 \%$ leve, $10 \%$ moderado y $0 \%$ severo; dinámico $85,9 \%, 12,4 \%$ y $1,2 \%$ respectivamente. El segundo día EVA reposo fue $94,1 \%$ leve y $5,9 \%$ moderado; dinámico $92,2 \%, 6,9 \%$ y $1 \%$ respectivamente. En la tabla 1 se describe la mediana de dolor según EVA por patologías. Se produjo falla de catéter en $6,4 \%$, $62,5 \%$ por salida accidental, $18,8 \%$ desplazamiento, $12,5 \%$ disnea y $6,3 \%$ corte accidental.

Conclusiones: De acuerdo a las cifras presentadas, el bloqueo interescalénico continuo es una alternativa válida para la analgesia postoperatoria, dado que los pacientes presentaron dolor leve en la mayoría de los casos, tanto en reposo como dinámico. Además, la incidencia de complicaciones asociadas a catéter fue baja y ningu-

Tabla 1. Mediana de dolor según EVA en primer y segundo días postoperatorios de acuerdo a patologías

\begin{tabular}{|lcccc|}
\hline Diagnósticos & \multicolumn{1}{c}{ EVA Día 1 (mediana) } & \multicolumn{2}{c|}{ EVA Día 2 (mediana) } \\
\hline $\begin{array}{l}\text { Rotura del manguito rota- } \\
\text { dor }\end{array}$ & Estático & Dinámico & Estático & Dinámico \\
\hline $\begin{array}{l}\text { Luxación de hombro } \\
\text { Fractura de húmero proxi- } \\
\text { mal }\end{array}$ & 0 & 0 & 0 & 0 \\
\hline $\begin{array}{l}\text { Endoprótesis de hombro } \\
\text { Luxofractura de hombro }\end{array}$ & 0 & 0 & 0 & 0 \\
\hline
\end{tabular}


na de ellas fue de gravedad. Dicha modalidad analgésica constituye una buena opción para el manejo del dolor en el paciente hospitalizado y ambulatorio.

\section{Referencias}

1. Brian M. Ilfield, MD, MS. Continuous Peri- pheral Nerve Block: A Review of the Published Evidence. Anesth Analg 2011;113:90425.

2. Jeffrey M. Richman et al. Does Continuous Peripheral Nerve Block Provide Superior Pain Control to Opioids? A Meta-Analysis. Anesth Analg 2006;102:248.57. 